\title{
New virus isolates from Italian hydrothermal environments underscore the biogeographic pattern in archaeal virus communities
}

\author{
Diana P. Baquero ${ }^{1,2}$ - Patrizia Contursi ${ }^{3}$ Monica Piochi ${ }^{4}$ - Simonetta Bartolucci ${ }^{3}$ Ying Liu ${ }^{1}$ \\ Virginija Cvirkaite-Krupovic ${ }^{1} \cdot$ David Prangishvili $^{1,5} \cdot$ Mart Krupovic $^{1}{ }^{1}$
}

Received: 13 November 2019 / Revised: 28 March 2020 / Accepted: 31 March 2020 / Published online: 22 April 2020

(c) The Author(s), under exclusive licence to International Society for Microbial Ecology 2020

\begin{abstract}
Viruses of hyperthermophilic archaea represent one of the least understood parts of the virosphere, showing little genomic and morphological similarity to viruses of bacteria or eukaryotes. Here, we investigated virus diversity in the active sulfurous fields of the Campi Flegrei volcano in Pozzuoli, Italy. Virus-like particles displaying eight different morphotypes, including lemon-shaped, droplet-shaped and bottle-shaped virions, were observed and five new archaeal viruses proposed to belong to families Rudiviridae, Globuloviridae and Tristromaviridae were isolated and characterized. Two of these viruses infect neutrophilic hyperthermophiles of the genus Pyrobaculum, whereas the remaining three have rod-shaped virions typical of the family Rudiviridae and infect acidophilic hyperthermophiles belonging to three different genera of the order Sulfolobales, namely, Saccharolobus, Acidianus, and Metallosphaera. Notably, Metallosphaera rod-shaped virus 1 is the first rudivirus isolated on Metallosphaera species. Phylogenomic analysis of the newly isolated and previously sequenced rudiviruses revealed a clear biogeographic pattern, with all Italian rudiviruses forming a monophyletic clade, suggesting geographical structuring of virus communities in extreme geothermal environments. Analysis of the CRISPR spacers suggests that isolated rudiviruses have experienced recent host switching across the genus boundary, potentially to escape the targeting by CRISPR-Cas immunity systems. Finally, we propose a revised classification of the Rudiviridae family, with the establishment of six new genera. Collectively, our results further show that high-temperature continental hydrothermal systems harbor a highly diverse virome and shed light on the evolution of archaeal viruses.
\end{abstract}

Supplementary information The online version of this article (https:// doi.org/10.1038/s41396-020-0653-z) contains supplementary material, which is available to authorized users.

David Prangishvili

david.prangishvili@pasteur.fr

$\triangle$ Mart Krupovic

mart.krupovic@pasteur.fr

1 Archaeal Virology Unit, Department of Microbiology, Institut Pasteur, 75015 Paris, France

2 Sorbonne Université, Collège Doctoral, 7 Quai Saint-Bernard, 75005 Paris, France

3 Department of Biology, University of Naples Federico II, Naples, Italy

4 Istituto Nazionale di Geofisica e Vulcanologia, Sezione Osservatorio Vesuviano, Naples, Italy

5 Ivane Javakhishvili Tbilisi State University, Tbilisi 0179, Georgia

\section{Introduction}

One of the most remarkable features of hyperthermophilic archaea is the diversity and uniqueness of their viruses. Most of these viruses infect members of the phylum Crenarchaeota and are evolutionarily unrelated to viruses infecting bacteria, eukaryotes or even archaea thriving at moderate temperature [1-4]. Thus far, unique to hyperthermophilic archaea are rod-shaped viruses of the families Rudiviridae and Clavaviridae; filamentous enveloped viruses of the families Lipothrixviridae and Tristromaviridae; as well as spherical (Globuloviridae), ellipsoid (Ovaliviridae), droplet-shaped (Guttaviridae), coil-shaped (Spiraviridae) and bottle-shaped (Ampullaviridae) viruses [1, 5]. Hyperthermophilic archaea are also infected by two types of spindle-shaped viruses, belonging to the families Fuselloviridae and Bicaudaviridae [6,7]. Whereas bicaudaviruses appear to be restricted to hyperthermophiles, viruses distantly related to fuselloviruses are also known to infect hyperhalophilic archaea [8], marine hyperthermophilic 
archaea [9, 10] and marine ammonia-oxidizing archaea from the phylum Thaumarchaeota [11]. Finally, hyperthermophilic archaea are also infected by three groups of viruses with icosahedral virions, Turriviridae [12], Portogloboviridae [13] and two closely related, unclassified viruses infecting Metallosphaera species [14]. Portoglobovirus SPV1 is structurally and genomically unrelated to other known viruses [13, 15], whereas viruses structurally similar to turriviruses are widespread in all three domains of life $[1,16]$. Structural studies on filamentous and spindleshaped crenarchaeal viruses have illuminated the molecular details of virion organization and further underscored the lack of relationship to viruses of bacteria and eukaryotes [17-23].

The uniqueness of hyperthermophilic archaeal viruses extends to their genomes, with $\sim 75 \%$ of the genes lacking detectable homologs in sequence databases [24]. All characterized archaeal viruses have DNA genomes, which can be single-stranded (ss) or double-stranded (ds), linear or circular. Comparative genomic and bipartite network analyses have shown that viruses of hyperthermophilic archaea share only few genes with the rest of the virosphere [25]. Furthermore, with some exceptions (see below), most of the genes in archaeal viruses are family-specific [26]. These observations, in combination with the structural studies, led to the suggestion that crenarchaeal viruses have originated on multiple independent occasions and constitute a unique part of the virosphere [1].

Although the infection cycles of crenarchaeal viruses have been studied for just a handful of representatives, the available data has already provided valuable insight into the virus-host interaction strategies in archaea. Two different egress strategies have been elucidated. The enveloped virions of fusellovirus SSV1 are assembled at the host cell membrane and are released from the cell by a budding mechanism similar to that of some eukaryotic enveloped viruses [27]. By contrast, lytic crenarchaeal viruses belonging to three unrelated families, Rudiviridae, Turriviridae and Ovaliviridae, employ a unique release mechanism based on the formation of pyramidal protrusions on the host cell surface, leading to perforation of the cell envelope and release of intracellularly assembled mature virions [5, 28, 29]. Remarkably, the pyramids are formed by a single virus-encoded protein of less than 100 amino acids and the corresponding gene has been apparently exchanged horizontally among viruses from different families [30, 31]. Differently from bacteriophages, many hyperthermophilic archaeal viruses encode divergent glycosyltransferases of either GT-A or GT-B superfamily and some carry multiple gene copies, suggesting an important function [2, 24, 32]. Consistently, virions of many crenarchaeal viruses are glycosylated $[16,17,19,33,34]$, although the exact physiological role of the glycosylation remains unknown. A recent study has suggested that glycosylation confers solubility and stability to macromolecular assemblies, such as type 4 pili and potentially virions, in extreme environments [35]. Another functional group of proteins which is broadly distributed across different families of crenarchaeal viruses includes anti-CRISPR (Acr) proteins. Indeed, CRISPR-Cas systems are prevalent in archaea in general and hyperthermophiles in particular [36]. Recent studies have uncovered three families of Acr proteins widespread in archaeal viruses and plasmids, which block CRISPRCas systems of types I and III by different mechanisms [37-39].

Single-cell sequencing combined with environmental metagenomics of hydrothermal microbial community from Yellowstone National Park [40] led to the estimation that $>60 \%$ of cells contain at least one virus type and a majority of these cells contain two or more virus types [41]. However, despite their diversity, distinctiveness, and abundance, the number of isolated species of viruses infecting hyperthermophilic archaea remains low compared to that of the known eukaryotic or bacterial viruses [2]. Indeed, it has been estimated that only about $0.01-0.1 \%$ of viruses present in geothermal acidic environments have been isolated [42]. Similarly, using a combination of viral assemblage sequencing and network analysis, it has been estimated that out of 110 identified virus groups, less than $10 \%$ represent known archaeal viruses, suggesting that the vast majority of virus clusters represent unknown viruses, likely infecting archaeal hosts [43]. Furthermore, the evolution and structuring of virus communities in terrestrial hydrothermal settings remain poorly understood. Here, to improve understanding on these issues, we explored the diversity of archaeal viruses at the active solfataric field of the Campi Flegrei volcano [44-46] in Pozzuoli, Italy, namely, the Pisciarelli hydrothermal area. The field is known for hot acidic environmental conditions [46] and its microbial communities are dominated by extremophilic microbes [34, 47-50]. However, the area we selected is characterized by hydrothermal conditions that are continuously changing in the short term due to the volcano dynamics, which could have an effect on the composition of resident microbial communities and their viruses. We report on the isolation and characterization of five new archaeal viruses belonging to three different families and infecting hosts from five different crenarchaeal genera.

\section{Materials and methods}

Materials and Methods are available in the Supplementary Information. 


\section{Results}

\section{Diversity of virus-like particles in enrichment cultures}

Nine environmental samples (I1-I9) were collected from hot springs, mud pools and hydrothermally altered terrains of the solfataric fields of the Campi Flegrei volcano in Pozzuoli, Italy, with temperatures ranging from 81 to $96^{\circ} \mathrm{C}$ and $\mathrm{pH}$ values between 1 and 7 (Supplementary Information, Table S1). The enrichment cultures were obtained by inoculating the samples into different media favoring the growth of hyperthermophilic members of the genera Sulfolobus/Saccharolobus, Acidianus and Pyrobaculum [34, 51]. In particular, samples with acidic $\mathrm{pH}$ were inoculated into medium favoring the growth of Sulfolobus/ Saccharolobus and Acidianus species, whereas those with neutral $\mathrm{pH}$ were inoculated into the Pyrobaculum medium (see Supplementary Materials and Methods for details). Virus-like particles (VLPs) were collected from cell-free culture supernatants and visualized by transmission electron microscopy as described in Supplementary Information.

A variety of VLPs were detected in the Sulfolobus/Saccharolobus enrichment cultures of samples I 3 and I9 and the Pyrobaculum enrichment culture of sample I4 (Fig. 1). Based on virion morphologies, the VLPs detected in the two samples inoculated in Sulfolobus/Saccharolobus medium could be assigned to five archaeal virus families: Fuselloviridae (Fig. 1a), Bicaudaviridae (Fig. 1b), Ampullaviridae
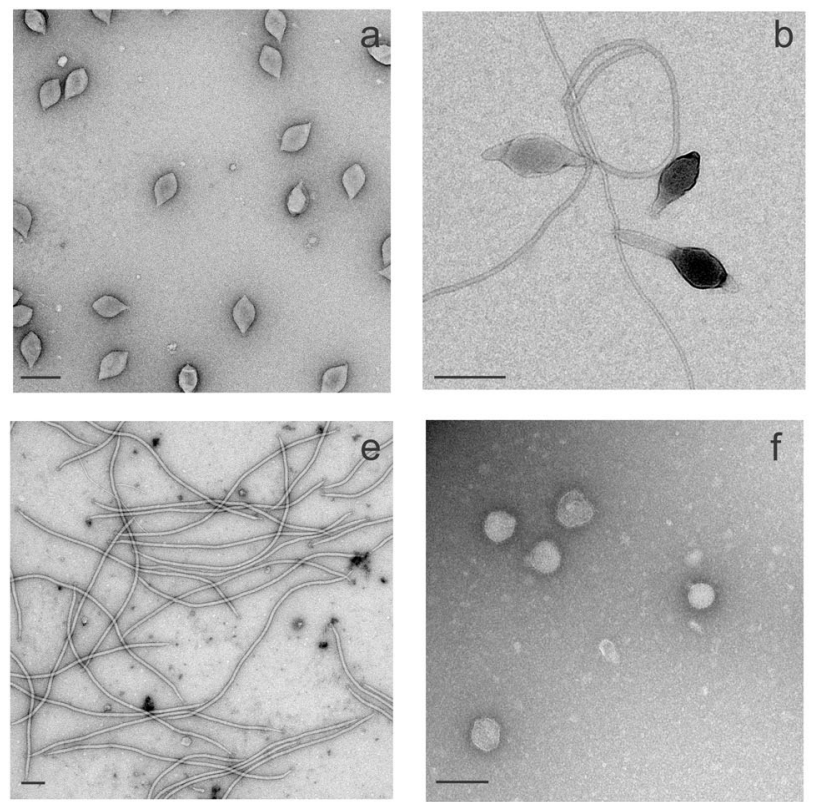

Fig. 1 Electron micrographs of the VLPs observed in enrichment cultures. a Fuselloviruses (tailless lemon-shaped virions). b Bicaudaviruses (large, tailed lemon-shaped virions). c Ampullaviruses (bottle-shaped virions). d Rudiviruses (rod-shaped virions).
(Fig. 1c), Rudiviridae (Fig. 1d) and Lipothrixviridae (Fig. 1e). VLPs propagated in the Pyrobaculum medium resembled members of the families Globuloviridae (Fig. 1f), Tristromaviridae (Fig. 1g) and Guttaviridae (Fig. 1h). We next set out to establish pure cultures of these different viruses and to isolate their respective hosts.

\section{Isolation of virus-host pairs}

In order to isolate VLP-propagating strains, 215 singlestrain isolates were colony purified from the enrichment cultures established in the Sulfolobus/Saccharolobus medium of the VLP-producing samples I3 and I9. Concentrated VLPs were first tested against the isolates by spot test. In case of cell growth inhibition, a liquid culture of the isolate was established and infected with the halo zone observed in the spot test. The production of the viral particles was subsequently verified by TEM. As a result, three strains replicating VLPs were identified. Comparison of their $16 \mathrm{~S}$ rRNA gene sequences showed that the three strains belong to three different genera of the order Sulfolobales, namely, Saccharolobus (until recently known as Sulfolobus), Acidianus and Metallosphaera. The 16S rRNA genes of these strains, POZ9, POZ149 and POZ202, respectively, displayed 100,99 , and $99 \%$ identity to the corresponding genes of Acidianus brierleyi DSM 1651 (NZ_CP029289), Saccharolobus solfataricus Ron 12/III (X90483) and Metallosphaera sedula SARC-M1 (CP012176). Rodshaped particles of different lengths were propagated
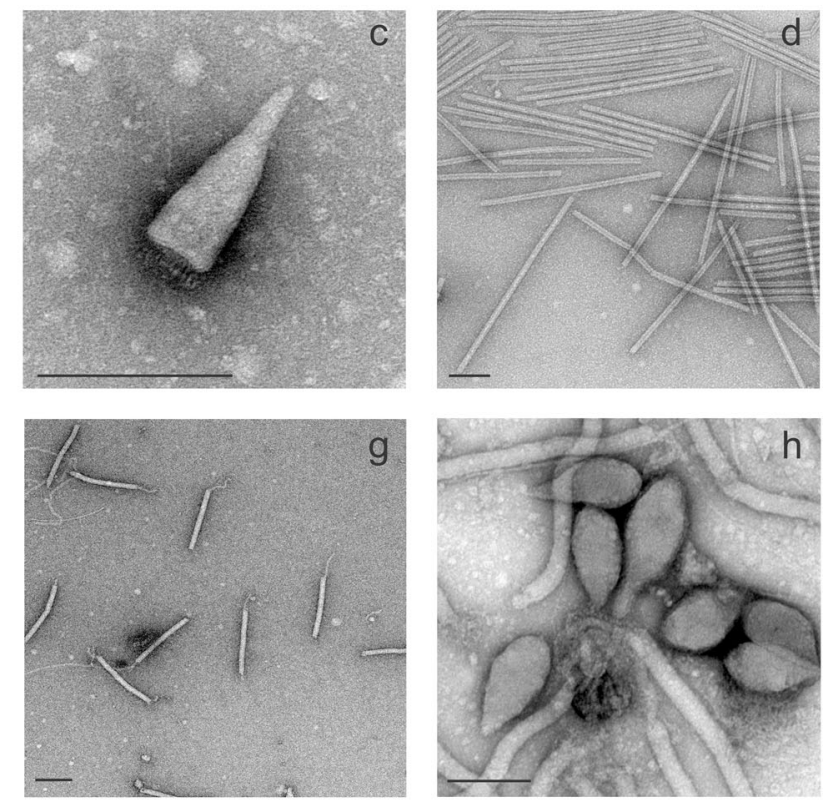

e Lipothrixviruses (filamentous virions). f Globuloviruses (spherical enveloped virions). $\mathbf{g}$ Tristromaviruses (filamentous enveloped virions). h Guttaviruses (droplet-shaped virions). Samples were negatively stained with $2 \%$ (wt/vol) uranyl acetate. Scale bars: $200 \mathrm{~nm}$. 
Fig. 2 Electron micrographs of the five isolated viruses.

a Metallosphaera rod-shaped

virus 1 . b Acidianus rod-shaped

virus 3. c Saccharolobus

solfataricus rod-shaped virus 1 .

d Pyrobaculum filamentous

virus 2. e Pyrobaculum spherical

virus 2 . Samples were

negatively stained with $2 \%$ (wt/ vol) uranyl acetate. Scale bars: $500 \mathrm{~nm}$; in insets: $100 \mathrm{~nm}$.
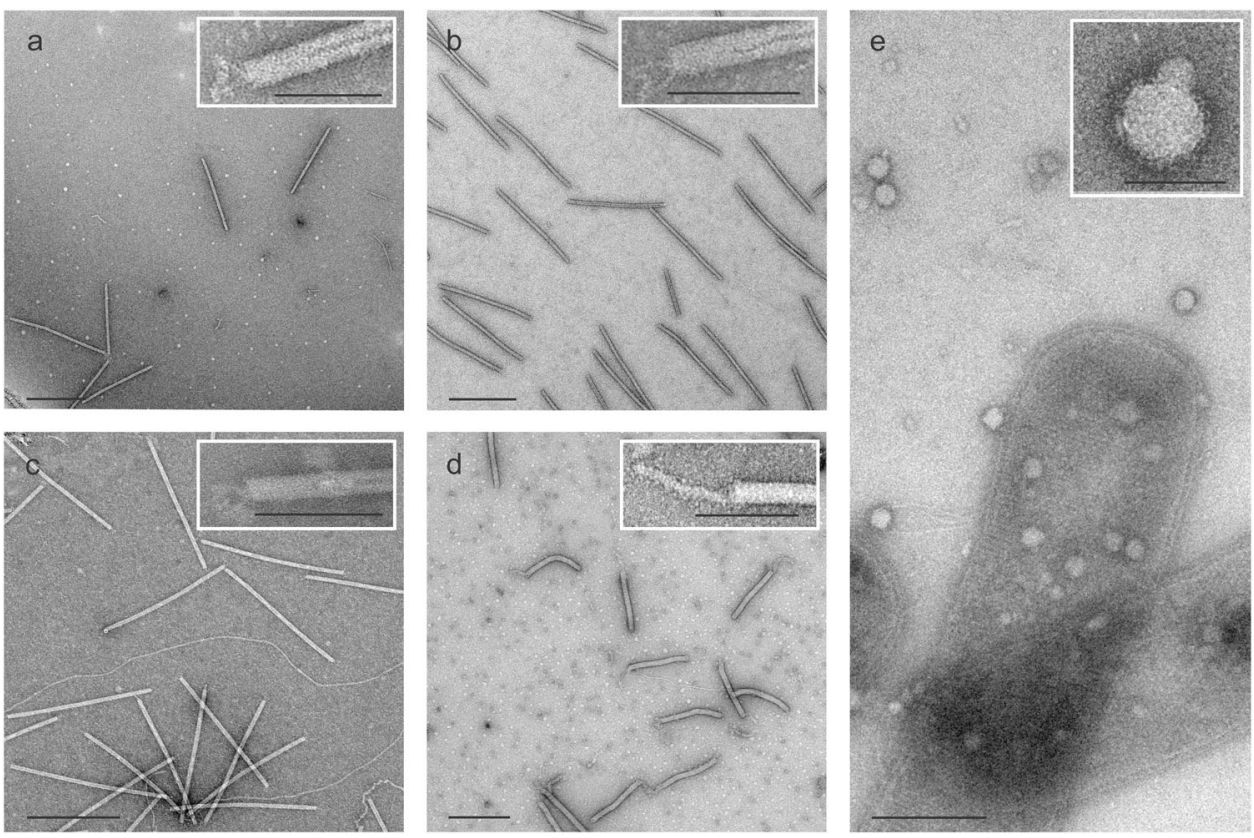

successfully in the three isolated strains (Fig. 2a-c) and, following the nomenclature used for other rudiviruses, were named Metallosphaera rod-shaped virus 1 (MRV1), Acidianus rod-shaped virus 3 (ARV3) and Saccharolobus solfataricus rod-shaped virus 1 (SSRV1), respectively.

Negatively stained MRV1, ARV3, and SSRV1 virions are rod-shaped particles measuring $630 \pm 20 \times 25 \pm 2 \mathrm{~nm}$, $670 \pm 40 \times 23 \pm 4 \mathrm{~nm}$ and $750 \pm 30 \times 24 \pm 3 \mathrm{~nm}$, respectively (Fig. 2a-c). Similar to members of the Rudiviridae family, the three viral particles have terminal fibers located at each end of the virion, which have been shown to play a role in host recognition in the case of Sulfolobus islandicus rodshaped virus 2 (SIRV2) [52].

The three rudiviruses displayed different infection dynamics. Infection of $S$. solfataricus POZ149 cultures with SSRV1 $(\mathrm{MOI}=3)$ resulted in severe growth retardation (Fig. S1a). The optical density of infected cultures remained constant for the first $24 \mathrm{hpi}$, similar to what has been reported previously for the prototypical rudivirus SIRV2 [28]. By contrast, infection with MRV1 and ARV3 had no apparent effect on the growth of M. sedula POZ202 and A. brierleyi POZ9, respectively (Fig. S1a). Nevertheless, production of extracellular virions was detected in all three cultures, starting at 8 (for SSRV1) or 12 (for MRV1 and ARV3) hpi and peaking at 24-32 hpi (Fig. S2).

A different approach was chosen to identify the hosts of the viral particles detected in the Pyrobaculum medium. Exponentially growing liquid cultures of Pyrobaculum strains were mixed with concentrated VLPs and incubated for 15 days at $90^{\circ} \mathrm{C}$ (see Supplementary Materials and Methods). The replication of the particles was monitored by TEM. $P$. arsenaticum 2GA propagated filamentous and spherical particles, named Pyrobaculum filamentous virus 2 (PFV2; Fig. 2d) and Pyrobaculum spherical virus 2 (PSV2; Fig. 2e), respectively. Because P. arsenaticum 2GA could not be grown as a lawn on solid medium, dilutions of infected cells were made in order to establish cultures infected with just one type of viral particles.

Negatively stained virions of PFV2 are filamentous and flexible particles of about $450 \pm 20 \times 34 \pm 4 \mathrm{~nm}$ in size with terminal filaments of up to $130 \mathrm{~nm}$ in length attached to one or both ends of the virions (Fig. 2d), similar to what has been reported for PFV1 [34]. PSV2 virions are spherical particles of around $90 \pm 20 \mathrm{~nm}$ of diameter, with a variable number of bulging protrusions on their surface (Fig. 2e), resembling Pyrobaculum spherical virus (PSV) particles [50]. Unfortunately, the hosts for other VLPs shown in Fig. 1 could not be isolated, either due to unfavorable growth under laboratory conditions or due to virusmediated extinction of the corresponding host cell populations.

Infection of $P$. arsenaticum 2GA with PSV2 resulted in a slight retardation of the host growth, with no detectable cell debris throughout the incubation, suggesting that the virus is not lytic (Fig. S1b). By contrast, infection with the filamentous virus PFV2 resulted in growth retardation of $P$. arsenaticum 2GA. This observation is consistent with the previous results showing that the closely related virus PFV1 lyses its host through an unknown mechanism [34].

\section{Host range}

To test the host ranges of the five isolated viruses, strains of the family Sulfolobaceae available in our laboratory 
Table 1 Host range of the archaeal viruses isolated in this study.

\begin{tabular}{|c|c|c|c|c|c|}
\hline \multirow[t]{2}{*}{ Archaeal strain } & \multicolumn{5}{|c|}{ Newly-isolated archaeal virus } \\
\hline & MRV1 & ARV3 & SSRV1 & PSV2 & PFV2 \\
\hline Metallosphaera sedula $\mathrm{POZ} 202$ & $\mathrm{H}$ & - & - & - & - \\
\hline Acidianus brierleyi $\mathrm{POZ9}$ & $-*$ & $\mathrm{H}$ & - & - & - \\
\hline Acidianus convivator & - & $-*$ & $-*$ & - & - \\
\hline Acidianus hospitalis $\mathrm{W} 1$ & - & $+^{*}$ & $-*$ & - & - \\
\hline Saccharolobus solfataricus $\mathrm{P} 1$ & - & - & $-*$ & - & - \\
\hline Saccharolobus solfataricus $\mathrm{P} 2$ & $-*$ & - & $-*$ & - & - \\
\hline Saccharolobus solfataricus POZ149 & - & - & $\mathrm{H}$ & - & - \\
\hline Sulfolobus islandicus LAL14/1 & - & - & -* & - & - \\
\hline Sulfolobus islandicus REN2H1 & - & - & - & - & - \\
\hline Sulfolobus islandicus HVE10/4 & - & - & $-*$ & - & - \\
\hline Sulfolobus islandicus REY15A & - & - & - & - & - \\
\hline Sulfolobus islandicus $\Delta \mathrm{C} 1 \mathrm{C} 2$ & - & - & - & - & - \\
\hline Sufolobus acidocaldarius DSM 639 & - & - & - & - & - \\
\hline Pyrobaculum arsenaticum PZ6 (DSM 13514) & - & - & - & $-*$ & - \\
\hline Pyrobaculum arsenaticum 2GA & - & - & - & $\mathrm{H}$ & $\mathrm{H}$ \\
\hline Pyrobaculum calidifontis VA1 (DSM 21063) & - & - & - & - & - \\
\hline Pyrobaculum oguniense TE7 (DSM 13380) & - & - & - & -* & $+^{*}$ \\
\hline
\end{tabular}

collection (Table 1) were infected with MRV1, ARV3, and SSRV1, whereas strains of Pyrobaculum (Table 1) were infected with PSV2 and PFV2. The production of virions was verified by spot test (for MRV1, ARV3 and SSRV1) and TEM. Only two strains were found to serve as additional hosts for ARV3 and PFV2. A. hospitalis W1 supported the propagation of ARV3, whereas $P$. oguniense TE7 served as a host of PFV2 (see Supplementary Materials and Methods for details).

We next investigated whether the infection in most of the tested strains is blocked prior or following the entry into the cell. To this end, the corresponding cells were incubated with the virus for $1 \mathrm{~h}$, excess of the viruses was removed by extensive washes and presence of the viral DNA in the cells was tested by PCR. SSRV1 DNA could be detected in the largest number of strains. In addition to the host $S$. solfataricus POZ149 cells, SSRV1 DNA was present in $A$. convivator, A. hospitalis W1, S. solfataricus strains $\mathrm{P} 1$ and P2 as well as in S. islandicus strains HVE10/4 and LAL14/1 (Table 1 and Fig. S3a). Notably, however, adsorption assay (see Supplementary Materials and Methods) did not show appreciable binding of SSRV1 virions to most of the nonhost strains (Fig. S4), consistent with the lower sensitivity of the latter assay compared to PCR. Indeed, the signal of SSRV1 DNA amplification was substantially fainter in the non-host cells, compared to the designated host. ARV3 DNA was detected in all three Acidianus strains, whereas that of MRV1, in addition to the host Metallosphaera strain, was found in A. brierleyi POZ9 and S. solfataricus P2 (Table 1 and Fig. S3b,c). These results suggest that MRV1 is able to deliver its DNA into cells from three different genera isolated in the same location, but the infection is blocked at a later, post-entry stage of the infection cycle.

PFV2 DNA was detected in $P$. arsenaticum 2GA and $P$. oguniense TE7 cultures, consistent with the observations made by TEM (Table 1, Fig. S3d), whereas PSV2 genome was detected not only in the host strain but also in $P$. oguniense TE7 and P. arsenaticum PZ6 (Fig. S3e), although no virions were observed in the latter strains by TEM.

\section{Genome organization}

Genomes of the five viruses were isolated from the purified virions and treated with DNase I, type II restriction endonucleases (REases) and RNase A. None of the viral genomes were sensitive to RNase A, but could be digested by DNase I and REases, indicating that all viral genomes consist of dsDNA molecules. The genomes were sequenced on Illumina MiSeq platform, with the assembled contigs corresponding to complete or near-complete virus genomes. The general properties of the virus genomes are summarized in Table 2.

\section{New species in the Globuloviridae family}

The linear dsDNA genome of PSV2 is 18,212 bp in length and has a GC content of $45 \%$, which is similar to that of other Pyrobaculum-infecting viruses (45-48\%) [34, 50]. The coding region of the PSV2 genome is flanked by 
Table 2 Genomic features of the hyperthermophilic archaeal viruses isolated in this study.

\begin{tabular}{llllllll}
\hline Virus & Host & Size (bp) & TIR & Topology & GC\% & ORFs & Accession \# \\
\hline MRV1 & Metallosphaera sedula POZ202 & 20269 & + & linear & 34.12 & 27 & MN876843 \\
ARV3 & Acidianus brierleyi POZ9 & 23666 & - & linear & 32.02 & 33 & MN876842 \\
SSRV1 & Saccharolobus solfataricus POZ149 & 26097 & - & linear & 32.31 & 37 & MN876841 \\
PSV2 & Pyrobaculum arsenaticum 2GA & 18212 & + & linear & 45.01 & 32 & MN876845 \\
PFV2 & Pyrobaculum arsenaticum 2GA & 17602 & + & linear & 45.32 & 39 & MN876844 \\
\hline
\end{tabular}

$T I R$ terminal inverted repeats, ORFs open reading frames.

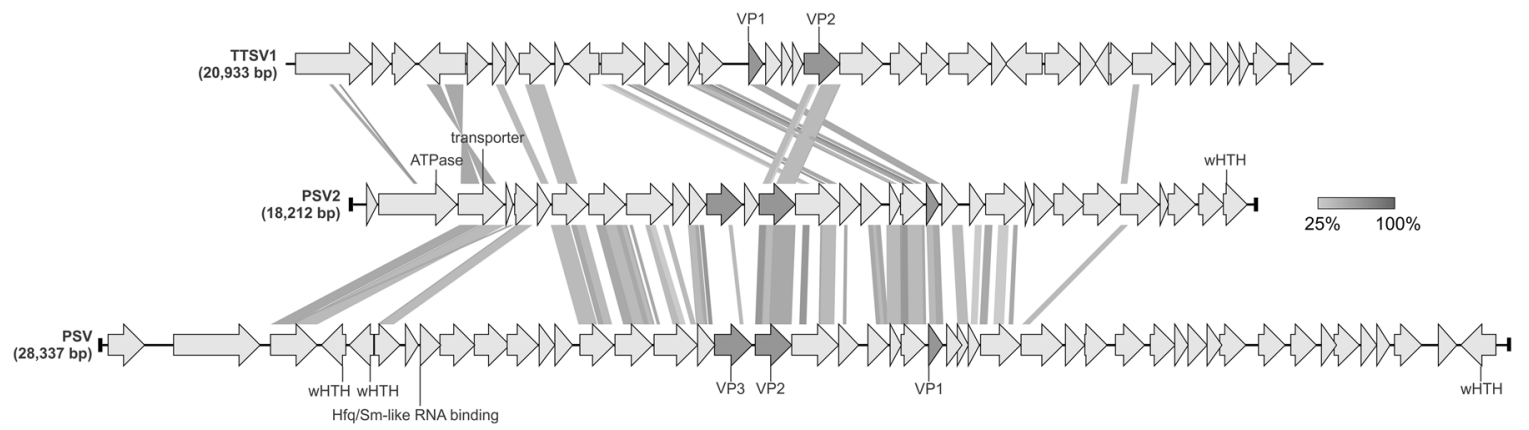

Fig. 3 Genome alignment of the three members of the Globuloviridae family. The open reading frames (ORFs) are represented by arrows that indicate the direction of transcription. The terminal inverted repeats (TIRs) are denoted by black bars at the ends of the genomes. Genes encoding the major structural proteins are shown in dark gray. The functional annotations of the predicted ORFs are depicted above/below the corresponding ORF. Homologous ORFs and ORF fragments are connected by shading in grayscale based on the level of amino acid sequence identity between the homologous regions. VP, virion protein; wHTH, winged helix-turn-helix domain. perfect $55 \mathrm{bp}$-long terminal inverted repeats (TIR), confirming the linear topology and (near) completeness of the genome. It contains 32 predicted open reading frames (ORFs), all located on the same strand. Thirteen PSV ORFs contain at least one predicted membrane-spanning region. Notably, two of them (ORFs 3 and 9) have nine predicted transmembrane domains (Table S2).

Globuloviruses stand out as some of the most mysterious among archaeal viruses, with $98 \%$ of their proteins showing no similarity to sequences in public databases and lacking functional annotation [24]. Homologs of PSV2 proteins were identified exclusively in members of the Globuloviridae (Fig. 3), corroborating the initial affiliation of PSV2 into the family Globuloviridae based on the morphological features of the virion. Nineteen PSV2 ORFs, including those encoding the three major structural proteins (VP1-VP3) [53], have closest homologs in PSV [50] with amino acid sequence identities ranging between $28 \%$ and $65 \%$ (Fig. 3); 13 of these ORFs are also shared with Thermoproteus tenax spherical virus 1 (TTSV1; $\mathrm{E}<1 \mathrm{e}-05)$, the only other characterized member of the Globuloviridae family [54]. The remaining 13 PSV2 ORFs yielded no significant matches to sequences in public databases. The three genomes display no appreciable similarity at the nucleotide sequence level, indicating considerable sequence diversity within the Globuloviridae family. Notably, among five PSV proteins for which high-resolution structures are available [32], only one protein with a unique fold, PSV gp11 (ORF239), is conserved in PSV2 $(\mathrm{E}=2 \mathrm{e}-17)$.

Sensitive profile-profile comparisons using HHpred allowed functional annotation of only four PSV2 proteins. The PSV2 ORF2 encodes a protein with an AAA + ATPase domain, which is most closely related to those found in ClpB-like chaperones and heat shock proteins (HHpred probability of 99.6\%; Supplementary Information, Table S2). ORF3 encodes one of the two proteins with nine putative transmembrane domains and is predicted to function as a membrane transporter, most closely matching bacterial and archaeal cation exchangers (HHpred probability of $95.5 \%$ ). Interestingly, the product of ORF4 is predicted to be a circadian clock protein KaiB, albeit with a lower probability (HHpred probability of 93\%). Finally, ORF32 shares homology with a putative transcriptional regulator with the winged helix-turn-helix domain (wHTH) of $S$. solfataricus (HHpred probability of 94.4\%). In addition, ORF11 encodes a functionally uncharacterized DUF1286-family protein conserved in archaea and several Saccharolobus-infecting viruses (HHpred probability of 99.5\%; Supplementary Information, Table S2).

\section{New species in the Tristromaviridae family}

The linear genome of PFV2 is 17,602 bp long and contains 39 ORFs, all except one located on the same strand. The coding region is flanked by $59 \mathrm{bp}-$ long TIRs. The GC 
content $(45.3 \%)$ of the genome is similar to that of PSV2 and other Pyrobaculum-infecting viruses [34, 50], but is considerably lower than in $P$. arsenaticum PZ6 $(58.3 \%)$, and $P$. oguniense TE7 (55.1\%). Eleven of the PFV2 ORFs were predicted to encode proteins with one or more membrane-spanning domains (Supplementary Information, Table S3).

The PFV2 genome is $98.9 \%$ identical over $70 \%$ of its length to that of PFV1, the type species of the Tristromaviridae family [55]. PFV1 and PFV2 were isolated $\sim 3$ years apart, from the same solfataric field in Pozzuoli [34], suggesting that the population of tristromaviruses is relatively stable over time. Accordingly, 36 of the 39 PFV2 ORFs are nearly identical to those of PFV1, with the ORFs encoding the three major structural proteins (VP1, VP2 and VP3) showing amino acid sequence identities higher than 96.6\% (Supplementary Information, Table S3). Two events account for the differences between PFV1 and PFV2: (i) a deletion spanning most of the PFV1 gene 27 (including codons 72-495) as well as the downstream genes 28-30, and (ii) insertion of a four-gene block between PFV1 genes 36 and 37 in PFV2 (Fig. 4). PFV1 gene 27 encodes a minor virion protein, whereas genes 29 and 30 encode putative lectin-like carbohydrate-binding proteins [34]. The absence of the corresponding genes in PFV2 genome suggests that they are dispensable for the PFV1/PFV2 infection cycle. Notably, a homolog of the PFV1 glycoside hydrolase gene 28 is reinserted into PFV2 genome as part of the four-gene block (PFV2 ORF34). However, the two genes do not appear to be orthologous in PFV1 and PFV2 genomes, because they share much lower sequence similarity compared to other orthologous genes $(50 \%$ versus average $96.5 \%$ identity). By contrast, PFV2 ORF35 has no counterpart in PFV1 but is homologous to the glycosyltransferase gene of Thermoproteus tenax virus 1 (TTV1) [56], the only other known member of the Tristromaviridae family [55] (Fig. 4). Thus, comparison of the closely related tristromavirus sequences revealed active genome remodeling in this virus group, involving both deletions and horizontal acquisition of new genes.

\section{New rod-shaped viruses}

The linear genomes of the isolated rudiviruses have a length ranging from 20,269 to $26,079 \mathrm{bp}$ and a GC content varying between 32.02 and $34.12 \%$. The MRV1 genome contains 80 bp-long TIR, suggesting that the genome is codingcomplete (i.e., contains all protein-coding genes). Although no TIRs could be identified for ARV3 and SSRV1, comparison with the genomes of other rudiviruses (Fig. 5) suggests that the two genomes are also nearly complete.

The genomes of MRV1, ARV3, and SSRV1 contain 27, 33, and 37 ORFs, respectively (Supplementary Tables S4-S6), and display high degree of gene synteny (Fig. 5). Comparison of the three genomes showed that they share 26 putative proteins, with amino acid sequence identities ranging between $35.1 \%$ and $93.9 \%$. Among the previously reported rudiviruses, the three newly isolated viruses share the highest similarity with ARV2 (ANI of $\sim 78 \%$ ), which was metagenomically sequenced from samples collected in the same Pozzuoli area [49]; this group of viruses shares 20 genes.

Rudiviruses represent one of the most extensively studied families of archaeal viruses with many of the viral proteins being functionally and structurally characterized [57]. Most of the MRV1, ARV3 and SSRV1 ORFs have orthologs in at least one other member of the Rudiviridae. For instance, $96 \%, 76 \%$, and $84 \%$ of the MRV1, ARV3, and SSRV1 ORFs, respectively, have orthologs in ARV2. Genes shared with other rudiviruses include those for the major and minor capsid proteins, several transcription factors with ribbon-helix-helix motifs, three glycosyltransferases, GCN5-family acetyltransferase, Holliday junction resolvase, SAM-dependent methyltransferase and a gene cassette encoding the ssDNA-binding protein, ssDNA annealing ATPase and Cas4-like ssDNA exonuclease

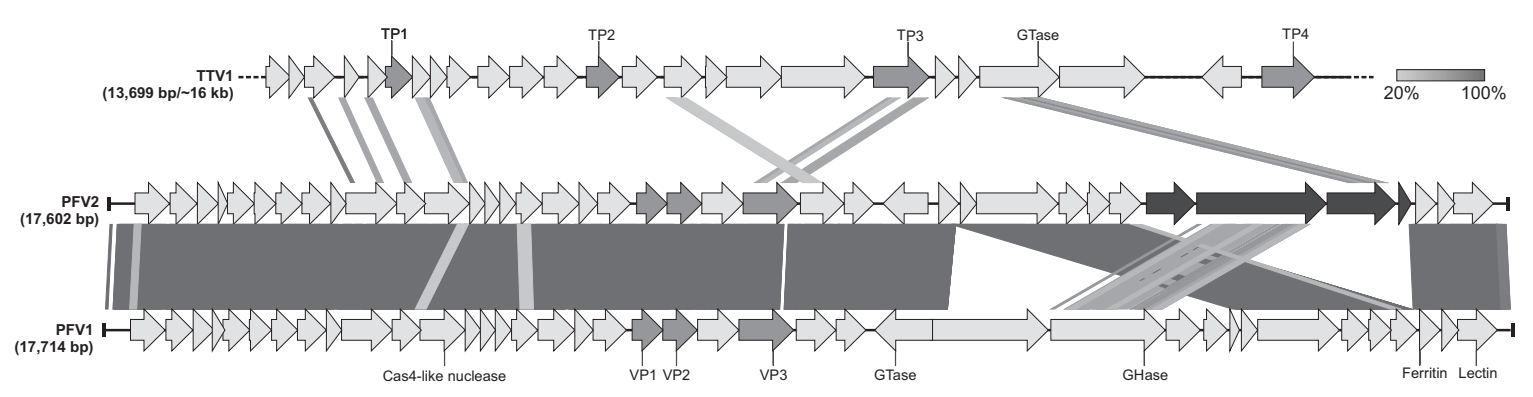

Fig. 4 Genome comparison of the three members of the Tristromaviridae family. The open reading frames (ORFs) are represented by arrows that indicate the direction of transcription. The terminal inverted repeats (TIRs) are denoted by black bars at the ends of the genomes. Genes encoding the major structural proteins are shown in dark gray, whereas the four-gene block discussed in the text is shown in black. The functional annotations of the predicted ORFs are depicted above/below the corresponding ORFs. Homologous genes are connected by shading in grayscale based on the level of amino acid sequence identity. The dotted line represents the incompleteness of the TTV1 genome. GHase, glycoside hydrolase; GTase, glycosyltransferase; TP/VP, virion protein. 


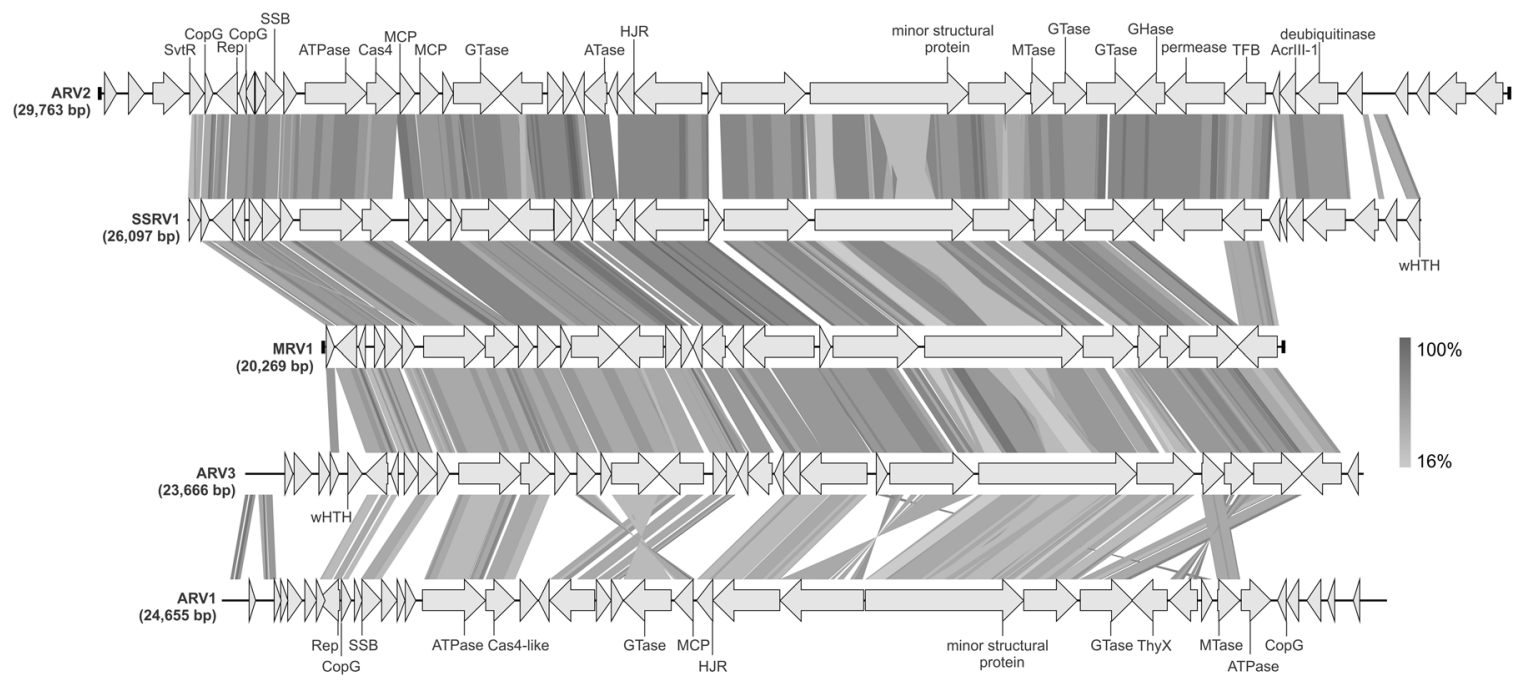

Fig. 5 Genome alignment of the Italian rudiviruses. ARV3, MRV1, and SSRV1 are newly isolated members of the Rudiviridae family, whereas ARV1 and ARV2 were reported previously [49, 68]. The open reading frames (ORFs) are represented by arrows that indicate the direction of transcription. The terminal inverted repeats (TIRs) are denoted by black bars at the ends of the genomes. The functional annotations of the predicted ORFs are depicted above/below the corresponding ORFs. Homologous genes are connected by shading in

(Fig. 5). The conservation of these core proteins in the expanding collection of rudiviruses underscores their critical role in viral reproduction. Conspicuously missing from the MRV1 and ARV3 are homologs of the SIRV2 P98 protein responsible for the formation of pyramidal structures for virion egress [30]. Cells infected with ARV3 and MRV1 were imaged by transmission electron microscopy at the peak of virion release ( 24 and $32 \mathrm{hpi}$; Fig. S2), but no evident pyramids were observed on the surface of the infected cells (Fig. S5). Thus, the mechanisms of MRV1 and ARV3 egress remain enigmatic and deserve further investigation.

Homologs of known Acr proteins encoded by diverse crenarchaeal viruses [37-39] are also missing from MRV1 and ARV3 genomes. Notably, SSRV1 carries a gene for the recently characterized AcrIII-1, which blocks antiviral response of type III CRISPR-Cas systems by cleaving the cyclic oligoadenylate second messenger [37]. Given that CRISPR-Cas systems are highly prevalent in hyperthermophilic archaea [36], the lack of identifiable anti-CRISPR genes in MRV1 and ARV3 is somewhat unexpected, suggesting that the two viruses encode novel Acr proteins. Similarly, lack of the genes encoding recognizable P98-like pyramid proteins in MRV1 and ARV3 (as well as in ARV1 and ARV2) suggests that these viruses have evolved a different solution for virion release.

Besides the core genes, rudiviruses are known to carry a rich complement of variable genes, which typically occupy the termini of linear genomes and are shared with viruses grayscale based on the amino acid sequence identity. AcrIII-1, antiCRISPR protein blocking type III CRISPR-Cas systems; ATase, acetyltransferase; CopG, ribbon-helix-helix motif-containing transcription regulator; GHase, glycoside hydrolase; GTase, glycosyltransferase; HJR, Holliday junction resolvase; MCP, major capsid protein; MTase, methyltransferase; Rep, replication initiation protein; SSB, ssDNA binding protein; TFB, Transcription factor B; ThyX, thymidylate synthase; wHTH, winged helix-turn-helix domain.

isolated from the same geographical location [58]. For instance, MRV1, ARV3, and SSRV1 carry several genes, which are exclusive to Italian rudiviruses. These include a divergent glycoside hydrolase, putative metal-dependent deubiquitinase, alpha-helical DNA-binding protein, transcription initiation factor and several short hypothetical proteins, which are likely candidates for Acrs (Supplementary Information, Tables S4-S6). Notably, some of these hypothetical proteins are shared with other crenarchaeal viruses isolated from the same location. In particular, ARV3 ORFs 5 and 33 as well as SSRV1 ORF31 are homologous to the putative proteins of the bicaudaviruses Acidianus two-tailed virus (ATV) and ATV2, whereas SSRV1 ORF36 is conserved in lipothrixvirus Acidianus filamentous virus 6 .

\section{A biogeographic pattern in the Rudiviridae family}

To gain insight into the global architecture of the rudivirus populations and the factors that govern it, we performed phylogenomic analysis of all available rudivirus genomes using the Genome-BLAST Distance Phylogeny method implemented in VICTOR [59]. Our results unequivocally show that the 19 sequenced rudiviruses fall into six clades corresponding to the geographical origins of the virus isolation (Fig. 6), suggesting local adaptation of the corresponding viruses. Thus, on the global scale, horizontal spread of rudivirus virions between geographically remote continental hydrothermal systems appears to be restricted. 
Fig. 6 Inferred phylogenomic tree of all known members of the Rudiviridae family based on whole genome VICTOR [59] analysis at the amino acid level. The tree is rooted with lipothrixviruses, and the branch length is scaled in terms of the Genome BLAST Distance Phylogeny (GBDP) distance formula D6. Only branch support values $>70 \%$ are shown. For each genome, the abbreviated virus name, GenBank accession number and host organism (when known) are indicated. Question marks denote that the host is not known. The tree is divided into colored blocks according to the geographical origin of the compared viruses.

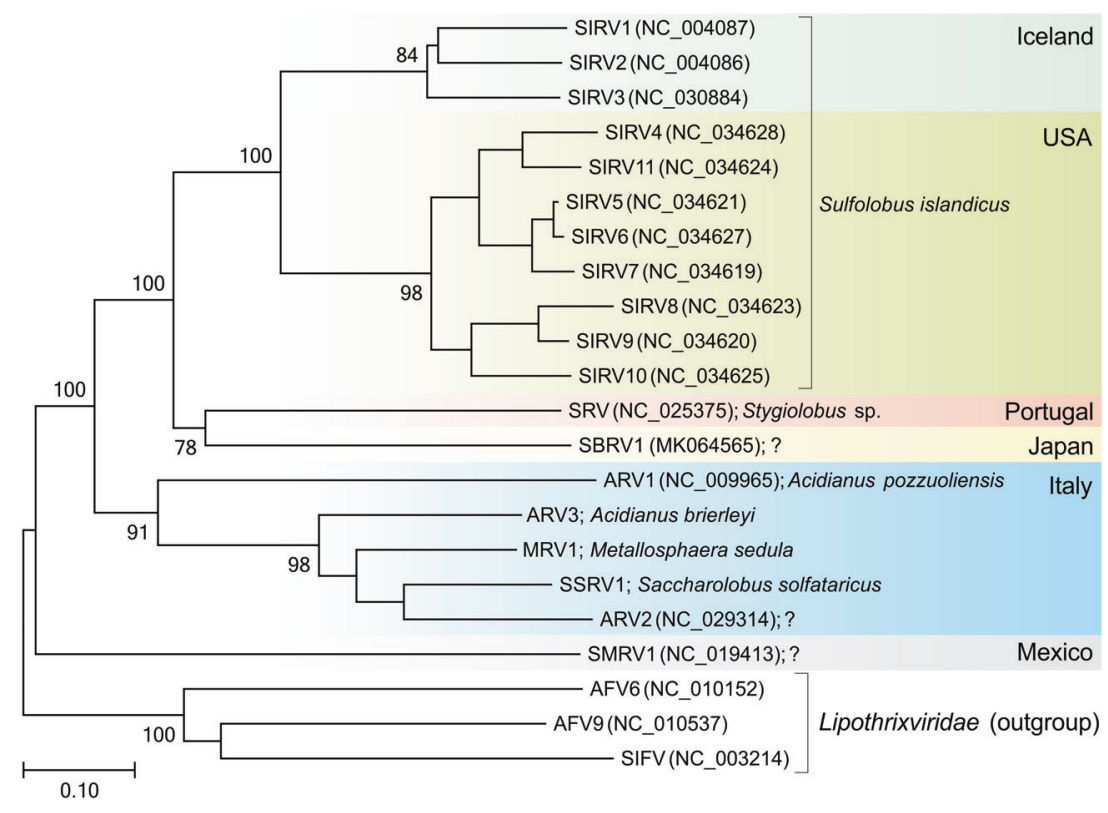

Revised classification of rudiviruses

Remarkably, despite forming a monophyletic group, all rudiviruses originating from Italy infect relatively distant hosts, belonging to three different genera of the order Sulfolobales. Such pattern was somewhat unexpected, because for all previously characterized rudiviruses, the genetic divergence of the viruses paralleled that of their respective hosts $[58,60]$. Thus, we hypothesized that such pattern of host specificities might signify host switching events in the history of the Italian rudivirus assemblage. CRISPR arrays, which contain spacer sequences derived from mobile genetic elements, keep memory of past infections and are commonly used as indicators for matching the uncultivated viruses to their potential hosts [61-63]. Thus, to investigate which hosts were exposed to Italian rudiviruses, we searched the CRISPRdb database [64] for the presence of spacers matching the corresponding viral genomes. Spacer matches were found for all five virus genomes, albeit with different levels of identity. Matches with $100 \%$ identity were obtained for ARV2, ARV3, SSRV1, and MRV1 (Supplementary Information, Table S7). Spacers matching ARV2 and ARV3 were found in Saccharolobus solfataricus P1, whereas ARV2 was also targeted by a CRISPR spacer (100\% identity) from Metallosphaera sedula DSM 5348. Unexpectedly, MRV1, which infects Metallosphaera species, was matched by spacers from different strains of S. solfataricus. Conversely, SSRV1 infecting S. solfataricus was targeted by multiple spacers from CRISPR arrays of M. sedula DSM 5348 (Supplementary Information, Table S7). These results are consistent with the possibility that in the recent history of Italian rudiviruses, host switching, even across the genus boundary, has been relatively common.
Of the 19 rudiviruses for which (near) complete genome sequences are available, only three (SIRV1, SIRV2, and ARV1) are officially classified. All three viruses are included in the same genus, Rudivirus. Here, we propose a taxonomic framework for classification of all cultivated and uncultured rudiviruses for which genome sequences are available. As mentioned above, phylogenomic analysis revealed six different clades (Fig. 6), highlighting considerable diversity of the natural rudivirus population, which has stratified into several assemblages, warranting their classification into distinct, genus-level taxonomic units. To this end, we compared the genome sequences using the Gegenees tool [65], which fragments the genomes and calculates symmetrical identity scores for each pairwise comparison based on BLASTn hits and a genome length. The analysis revealed seven clusters of related genomes, which were generally consistent with those obtained in the phylogenomic analysis (Table S8). Notably, due to considerable sequence divergence, ARV1 falls into a separate cluster from other Italian rudiviruses. Consistently, in the phylogenomic tree, ARV1 forms a sister group to other Italian rudiviruses. Furthermore, among the five Italian rudiviruses, the genome of ARV1 is most divergent, displaying multiple gene and genomic segment inversions and relocations compared to the other viruses (Fig. 5). Viruses from the seven clades also differ considerably in terms of the variable gene contents. For instance, viruses SIRV1 and SIRV2 isolated in Iceland share 11 genes that are absent from the USA SIRVs [58]. Thus, to acknowledge the differences between the known rudiviruses, we propose to classify them into seven 
genera: "Icerudivirus" (former Rudivirus, to include SIRV1-SIRV3), "Mexirudivirus" (SMRV1), "Azorudivirus" (SRV), "Itarudivirus" (ARV1), "Hoswirudivirus" (ARV2, ARV3, MRV1, SSRV1; hoswi-, for host switching), "Japarudivirus" (SBRV1) and "Usarudivirus" (SIRV4-SIRV11). We note that this classification would be consistent with the current practices of the International Committee on Taxonomy of Viruses (ICTV) to classify viruses based on their protein and genomic sequences [66].

\section{Discussion}

Here, we reported the results of our exploration of the diversity of hyperthermophilic archaeal viruses at the solfataric field in Pisciarelli, Pozzuoli. Previous sampling of archaeal viruses in the thermal springs in Pisciarelli led to the isolation of viruses from the families Ampullaviridae, Bicaudaviridae, Lipothrixviridae, Rudiviridae and Tristromaviridae [34, 67-70], whereas those of the families Fuselloviridae, Globuloviridae and Guttaviridae, which we observed in the initial enrichment cultures, have not been previously reported from the sampled Pisciarelli sites. Nevertheless, similar virion morphologies have been observed in high-temperature continental hydrothermal systems from other geographical locations across the globe [50, 71-74], pointing to global distribution of most groups of hyperthermophilic archaeal viruses. However, how these virus communities are structured and whether geographically remote hydrothermal ecosystems undergo virus immigration is not fully understood. Notably, metagenomics analysis of two hot springs located in Pozzuoli has shown that representatives of the Lipothrixviridae, Bicaudaviridae, Ampullaviridae and Rudiviridae families dominated the corresponding virus communities at the time of sampling, collectively amounting to over $90 \%$ of the sequencing reads [49]. We have observed virions representing all four virus families by TEM in our enrichment cultures, corroborating the results of the metagenomic sequencing, and could isolate three representatives of the Rudiviridae family.

A previous study has revealed a biogeographic pattern among $S$. islandicus-infecting rudiviruses isolated from hot springs in Iceland and United States [58]. That is, viruses from the same geographical location were more closely related to each other than they were to viruses from other locations and the larger the distance the more divergent the virus genomes were. Similar observation has been made for the Sulfolobus-infecting spindle-shaped viruses of the family Fuselloviridae [74-76]. By contrast, a study focusing on three relatively closely spaced hot springs in Yellowstone National Park concluded that horizontal virus movement, rather than mutation, is the dominant factor controlling the viral community structure [77].

Phylogenomic and comparative genomic analysis of the rudiviruses reported herein and those sequenced previously revealed a strong biogeographic pattern, suggesting that diversification and evolution of rudiviruses is influenced by spatial confinement within discrete hightemperature continental hydrothermal systems, with little horizontal migration of viral particles over large distances. Consistently, analyses of the CRISPR spacers carried by hyperthermophilic archaea predominantly target local viruses, further indicating geographically defined coevolution of viruses and their hosts [74, 78]. This is in stark contrast with the global architecture of virus communities associated with hyperhalophilic archaea, where genomic similarity between viruses does not correspond to geographical distance [79, 80]. Notably, however, it has been suggested that reversible silicification of virus particles, which is conceivable in hot spring environments, might promote long-distance host-independent virus dispersal [81].

We also show, for the first time, that relatively closely related rudiviruses infect phylogenetically distant hosts, belonging to three different genera. Interestingly, whereas ARV3 could deliver its DNA exclusively into Acidianus cells, the genomes of SSRV1 and MRV1 were detected not only in their respective Saccharolobus and Metallosphaera hosts, but also in the non-host Acidianus cells (Fig. S3). Given the basal position of Acidianus rudiviruses (Fig. 6), this pattern is best consistent with the host switch events in the history of Italian rudiviruses, whereby the ancestral Acidianus virus gained the ability to infect Saccharolobus and Metallosphaera hosts. At least in the case of rudivirises, relatively few genetic changes appear to be necessary for gaining the ability to infect a new host. In tailed bacteriophages, host range switches are typically associated with mutations in genes encoding the tail fiber proteins responsible for host recognition [82]. Several molecular mechanisms underlying mutability of the tail fiber genes have been described, including genetic drift, diversity generating retroelements and phase variation cassettes. The latter two systems have been demonstrated to function also in viruses infecting anaerobic methane-oxidizing (ANME) and hyperhalophilic archaea, respectively [83, 84]. Both mechanisms depend on specific enzymes, namely, reversetranscriptase and invertase. However, neither of the two systems is present in rudiviruses, suggesting that genetic drift is the most likely mechanism responsible for generating diversity in the gene(s) encoding receptor-binding protein(s) of rudiviruses.

Analysis of CRISPR spacers from hyperthermophilic archaea confirmed that viruses closely related to those isolated in this study were infecting highly different hosts in 
the recent past. Indeed, viruses infecting Saccharolobus and Metallosphaera species are targeted by spacers from CRISPR arrays of Metallosphaera and Saccharolobus, respectively (Table S7). This observation further reinforces a relatively recent host switch event. Notably, this phenomenon appears to be also applicable to rudiviruses from other geographical locations. In particular, SBRV1, a rudivirus from a Japanese hot spring [60], was found to be targeted by 521 unique CRISPR spacers associated with all four principal CRISPR repeat sequences present in Sulfolobales [78], suggesting either very broad host range or frequent host switches. Furthermore, we have recently shown that CRISPR targeting is an important factor driving the genome evolution of hyperthermophilic archaeal viruses [78]. Given the presence of multiple CRISPR spacers matching rudivirus genomes, we hypothesize that necessity to switch hosts might be, to a large extent, driven by CRISPR targeting. Notably, matching of CRISPR spacers to protospacers in viral genomes is one of the widely used approaches of host identification for viruses discovered by metagenomics, with the estimated host genus prediction accuracy of $70-90 \%[62,63,85]$. Our results suggest that in the case of rudiviruses, spacer matching might not provide accurate predictions beyond the rank of family (i.e., Sulfolobaceae).

Collectively, we show that terrestrial hydrothermal systems harbor a highly diverse virome represented by multiple families with unique virus morphologies not described in other environments. Genomes of the newly isolated viruses, especially those infecting Pyrobaculum species, remain a rich source of unknown genes, which could be involved in novel mechanisms of virus-host interactions. Furthermore, our results suggest that global rudivirus communities display biogeographic pattern and diversify into distinct lineages confined to discrete geographical locations. This diversification appears to involve relatively frequent host switching, potentially evoked by host CRISPR-Cas immunity systems. Future studies should focus on understanding the molecular changes allowing rudiviruses to efficiently infect and multiply in new hosts, attaining host range expansion and escaping CRISPR targeting.

\section{Data availability}

Genome sequences of the isolated viruses have been deposited in GenBank and their accession numbers are listed in Table 2.

Acknowledgements This work was supported by l'Agence Nationale de la Recherche (France) project ENVIRA (to M.K.) and the European Union's Horizon 2020 research and innovation program under grant agreement 685778 , project VIRUS X (to D.P.). Y.L. is a recipient of the Pasteur-Roux-Cantarini Fellowship from Institut Pasteur. D.P.B. is part of the Pasteur-Paris University (PPU) International PhD Program, which has received funding from the European Union's Horizon 2020 research and innovation programme under the Marie Sklodowska-Curie grant agreement No 665807. We are also grateful to the Ultrastructural BioImaging (UTechS UBI) unit of Institut Pasteur for access to electron microscopes and Marc Monot from the Biomics Platform of Institut Pasteur for helpful discussions on genome assembly.

\section{Compliance with ethical standards}

Conflict of interest The authors declare that they have no conflict of interest.

Publisher's note Springer Nature remains neutral with regard to jurisdictional claims in published maps and institutional affiliations.

\section{References}

1. Prangishvili D, Bamford DH, Forterre P, Iranzo J, Koonin EV, Krupovic M. The enigmatic archaeal virosphere. Nat Rev Microbiol. 2017;15:724-39.

2. Munson-McGee JH, Snyder JC, Young MJ. Archaeal viruses from high-temperature environments. Genes (Basel). 2018;9: E128.

3. Wang H, Peng N, Shah SA, Huang L, She Q. Archaeal extrachromosomal genetic elements. Microbiol Mol Biol Rev. 2015;79:117-52.

4. Dellas N, Snyder JC, Bolduc B, Young MJ. Archaeal Viruses: Diversity, Replication, and Structure. Annu Rev Virol. 2014;1: 399-426.

5. Wang H, Guo Z, Feng H, Chen Y, Chen X, Li Z, et al. Novel Sulfolobus virus with an exceptional capsid architecture. J Virol. 2018;92:e01727-17.

6. Krupovic M, Quemin ER, Bamford DH, Forterre P, Prangishvili D. Unification of the globally distributed spindle-shaped viruses of the Archaea. J Virol. 2014;88:2354-8.

7. Contursi P, Fusco S, Cannio R, She Q. Molecular biology of fuselloviruses and their satellites. Extremophiles. 2014;18: 473-89.

8. Bath C, Dyall-Smith ML. His1, an archaeal virus of the Fuselloviridae family that infects Haloarcula hispanica. J Virol. 1998;72:9392-5.

9. Gorlas A, Koonin EV, Bienvenu N, Prieur D, Geslin C. TPV1, the first virus isolated from the hyperthermophilic genus Thermococcus. Environ Microbiol. 2012;14:503-16.

10. Geslin C, Le Romancer M, Erauso G, Gaillard M, Perrot G, Prieur D. PAV1, the first virus-like particle isolated from a hyperthermophilic euryarchaeote, "Pyrococcus abyssi". J Bacteriol. 2003;185:3888-94.

11. Kim JG, Kim SJ, Cvirkaite-Krupovic V, Yu WJ, Gwak JH, Lopez-Perez M, et al. Spindle-shaped viruses infect marine ammonia-oxidizing thaumarchaea. Proc Natl Acad Sci USA. 2019;116:15645-50.

12. Rice G, Stedman K, Snyder J, Wiedenheft B, Willits D, Brumfield $\mathrm{S}$, et al. Viruses from extreme thermal environments. Proc Natl Acad Sci USA. 2001;98:13341-5.

13. Liu Y, Ishino S, Ishino $\mathrm{Y}$, Pehau-Arnaudet G, Krupovic M, Prangishvili D. A novel type of polyhedral viruses infecting hyperthermophilic archaea. J Virol. 2017;91:e00589-17.

14. Wagner C, Reddy V, Asturias F, Khoshouei M, Johnson JE, Manrique $\mathrm{P}$, et al. Isolation and characterization of Metallosphaera turreted icosahedral virus, a founding member of a new family of archaeal viruses. J Virol. 2017;91:e00925-17. 
15. Wang F, Liu Y, Su Z, Osinski T, de Oliveira GAP, Conway JF, et al. A packing for A-form DNA in an icosahedral virus. Proc Natl Acad Sci USA. 2019;116:22591-7.

16. Maaty WS, Ortmann AC, Dlakic M, Schulstad K, Hilmer JK, Liepold L, et al. Characterization of the archaeal thermophile Sulfolobus turreted icosahedral virus validates an evolutionary link among double-stranded DNA viruses from all domains of life. J Virol. 2006;80:7625-35.

17. Liu Y, Osinski T, Wang F, Krupovic M, Schouten S, Kasson P, et al. Structural conservation in a membrane-enveloped filamentous virus infecting a hyperthermophilic acidophile. Nat Commun. 2018;9:3360.

18. Hochstein R, Bollschweiler D, Dharmavaram S, Lintner NG, Plitzko JM, Bruinsma R, et al. Structural studies of Acidianus tailed spindle virus reveal a structural paradigm used in the assembly of spindle-shaped viruses. Proc Natl Acad Sci USA. 2018;115:2120-5.

19. Ptchelkine D, Gillum A, Mochizuki T, Lucas-Staat S, Liu Y, Krupovic M, et al. Unique architecture of thermophilic archaeal virus APBV1 and its genome packaging. Nat Commun. 2017; 8:1436.

20. Kasson P, DiMaio F, Yu X, Lucas-Staat S, Krupovic M, Schouten $\mathrm{S}$, et al. Model for a novel membrane envelope in a filamentous hyperthermophilic virus. Elife. 2017;6:e26268.

21. DiMaio F, Yu X, Rensen E, Krupovic M, Prangishvili D, Egelman EH. Virology. A virus that infects a hyperthermophile encapsidates A-form DNA. Science. 2015;348:914-7.

22. Hong C, Pietila MK, Fu CJ, Schmid MF, Bamford DH, Chiu W. Lemon-shaped halo archaeal virus His1 with uniform tail but variable capsid structure. Proc Natl Acad Sci USA. 2015;112: 2449-54.

23. Stedman KM, DeYoung M, Saha M, Sherman MB, Morais MC. Structural insights into the architecture of the hyperthermophilic Fusellovirus SSV1. Virology. 2015;474:105-9.

24. Krupovic M, Cvirkaite-Krupovic V, Iranzo J, Prangishvili D, Koonin EV. Viruses of archaea: Structural, functional, environmental and evolutionary genomics. Virus Res. 2018;244:181-93.

25. Iranzo J, Krupovic M, Koonin EV. The double-stranded DNA virosphere as a modular hierarchical network of gene sharing. MBio. 2016;7:e00978-16.

26. Iranzo J, Koonin EV, Prangishvili D, Krupovic M. Bipartite network analysis of the Archaeal Virosphere: evolutionary connections between viruses and capsidless mobile elements. J Virol. 2016;90:11043-55.

27. Quemin ER, Chlanda P, Sachse M, Forterre P, Prangishvili D, Krupovic M. Eukaryotic-like virus budding in archaea. MBio. 2016;7:e01439-16.

28. Bize A, Karlsson EA, Ekefjard K, Quax TE, Pina M, Prevost MC, et al. A unique virus release mechanism in the Archaea. Proc Natl Acad Sci USA. 2009;106:11306-11.

29. Brumfield SK, Ortmann AC, Ruigrok V, Suci P, Douglas T, Young MJ. Particle assembly and ultrastructural features associated with replication of the lytic archaeal virus sulfolobus turreted icosahedral virus. J Virol. 2009;83:5964-70.

30. Quax TE, Krupovic M, Lucas S, Forterre P, Prangishvili D. The Sulfolobus rod-shaped virus 2 encodes a prominent structural component of the unique virion release system in Archaea. Virology. 2010;404:1-4.

31. Snyder JC, Brumfield SK, Peng N, She Q, Young MJ. Sulfolobus turreted icosahedral virus c92 protein responsible for the formation of pyramid-like cellular lysis structures. J Virol. 2011;85:6287-92.

32. Krupovic M, White MF, Forterre P, Prangishvili D. Postcards from the edge: structural genomics of archaeal viruses. Adv Virus Res. 2012;82:33-62.
33. Quemin ER, Pietila MK, Oksanen HM, Forterre P, Rijpstra WI, Schouten $\mathrm{S}$, et al. Sulfolobus spindle-shaped virus 1 contains glycosylated capsid proteins, a cellular chromatin protein, and host-derived lipids. J Virol. 2015;89:11681-91.

34. Rensen EI, Mochizuki T, Quemin E, Schouten S, Krupovic M, Prangishvili D. A virus of hyperthermophilic archaea with a unique architecture among DNA viruses. Proc Natl Acad Sci USA. 2016;113:2478-83.

35. Wang F, Cvirkaite-Krupovic V, Kreutzberger MAB, Su Z, de Oliveira GAP, Osinski T, et al. An extensively glycosylated archaeal pilus survives extreme conditions. Nat Microbiol. 2019;4:1401-10.

36. Iranzo J, Lobkovsky AE, Wolf YI, Koonin EV. Evolutionary dynamics of the prokaryotic adaptive immunity system CRISPRCas in an explicit ecological context. J Bacteriol. 2013;195: 3834-44.

37. Athukoralage JS, McMahon SA, Zhang C, Grüschow S, Graham S, Krupovic M, et al. A viral ring nuclease anti-CRISPR subverts type III CRISPR immunity. Nature. 2020;577:572-5.

38. Bhoobalan-Chitty Y, Johansen TB, Di Cianni N, Peng X. Inhibition of type III CRISPR-Cas immunity by an archaeal virusencoded anti-CRISPR protein. Cell. 2019;179:448-58 e11.

39. He F, Bhoobalan-Chitty Y, Van LB, Kjeldsen AL, Dedola M, Makarova KS, et al. Anti-CRISPR proteins encoded by archaeal lytic viruses inhibit subtype I-D immunity. Nat Microbiol. 2018;3:461-9.

40. Hurwitz S, Lowenstern JB. Dynamics of the Yellowstone hydrothermal system. Rev Geophys. 2014;52:375-411.

41. Munson-McGee JH, Peng S, Dewerff S, Stepanauskas R, Whitaker RJ, Weitz JS, et al. A virus or more in (nearly) every cell: ubiquitous networks of virus-host interactions in extreme environments. ISME J. 2018;12:1706-14.

42. Snyder JC, Bateson MM, Lavin M, Young MJ. Use of cellular CRISPR (clusters of regularly interspaced short palindromic repeats) spacer-based microarrays for detection of viruses in environmental samples. Appl Environ Microbiol. 2010;76:7251-8.

43. Bolduc B, Wirth JF, Mazurie A, Young MJ. Viral assemblage composition in Yellowstone acidic hot springs assessed by network analysis. ISME J. 2015;9:2162-77.

44. Piochi M, Kilburn CRJ, Di Vito MA, Mormone A, Tramelli A, Troise $\mathrm{C}$, et al. The volcanic and geothermally active Campi Flegrei caldera: an integrated multidisciplinary image of its buried structure. Int Journ Earth Sci. 2014;103:401-21.

45. Piochi M, Mormone A, Balassone G, Strauss H, Troise C, De Natale G. Native sulfur, sulfates and sulfides from the active Campi Flegrei volcano (southern Italy): Genetic environments and degassing dynamics revealed by mineralogy and isotope geochemistry. J Volcano Geotherm Res. 2015;304:180-93.

46. Piochi M, Mormone A, Strauss H, Balassone G. The acid sulfate zone and the mineral alteration styles of the Roman Puteoli (Neapolitan area, Italy): clues on fluid fracturing progression at the Campi Flegrei volcano. Solid Earth. 2019;10:1809-31.

47. Menzel P, Gudbergsdottir SR, Rike AG, Lin L, Zhang Q, Contursi $\mathrm{P}$, et al. Comparative metagenomics of eight geographically remote terrestrial hot springs. Micro Ecol. 2015;70:411-24.

48. Ciniglia C, Yoon HS, Pollio A, Pinto G, Bhattacharya D. Hidden biodiversity of the extremophilic Cyanidiales red algae. Mol Ecol. 2004;13:1827-38

49. Gudbergsdóttir SR, Menzel P, Krogh A, Young M, Peng X. Novel viral genomes identified from six metagenomes reveal wide distribution of archaeal viruses and high viral diversity in terrestrial hot springs. Environ Microbiol. 2016;18:863-74.

50. Häring M, Peng X, Brugger K, Rachel R, Stetter KO, Garrett RA, et al. Morphology and genome organization of the virus PSV of the hyperthermophilic archaeal genera Pyrobaculum and 
Thermoproteus: a novel virus family, the Globuloviridae. Virology. 2004;323:233-42.

51. Zillig W, Kletzin A, Schleper C, Holz I, Janekovic D, Hain J, et al. Screening for Sulfolobales, their Plasmids and their Viruses in Icelandic Solfataras. Syst Appl Microbiol. 1993;16:609-28.

52. Quemin ER, Lucas S, Daum B, Quax TE, Kuhlbrandt W, Forterre $\mathrm{P}$, et al. First insights into the entry process of hyperthermophilic archaeal viruses. J Virol. 2013;87:13379-85.

53. Prangishvili D, Krupovic M, ICTV Report Consortium. ICTV virus taxonomy profile: Globuloviridae. J Gen Virol. 2018;99: 1357-8

54. Ahn DG, Kim SI, Rhee JK, Kim KP, Pan JG, Oh JW. TTSV1, a new virus-like particle isolated from the hyperthermophilic crenarchaeote Thermoproteus tenax. Virology. 2006;351:280-90.

55. Prangishvili D, Rensen E, Mochizuki T, Krupovic M, ICTV Report Consortium. ICTV Virus Taxonomy Profile: Tristromaviridae. J Gen Virol. 2019;100:135-6.

56. Neumann H, Schwass V, Eckerskorn C, Zillig W. Identification and characterization of the genes encoding three structural proteins of the Thermoproteus tenax virus TTV1. Mol Gen Genet. 1989;217:105-10.

57. Prangishvili D, Koonin EV, Krupovic M. Genomics and biology of Rudiviruses, a model for the study of virus-host interactions in Archaea. Biochem Soc Trans. 2013;41:443-50.

58. Bautista MA, Black JA, Youngblut ND, Whitaker RJ. Differentiation and Structure in Sulfolobus islandicus Rod-Shaped Virus Populations. Viruses. 2017;9:E120.

59. Meier-Kolthoff JP, Goker M. VICTOR: genome-based phylogeny and classification of prokaryotic viruses. Bioinformatics. 2017;33: 3396-404.

60. Liu Y, Brandt D, Ishino S, Ishino Y, Koonin EV, Kalinowski J, et al. New archaeal viruses discovered by metagenomic analysis of viral communities in enrichment cultures. Environ Microbiol. 2019;21:2002-14.

61. Roux S, Krupovic M, Daly RA, Borges AL, Nayfach S, Schulz F, et al. Cryptic inoviruses revealed as pervasive in bacteria and archaea across Earth's biomes. Nat Microbiol. 2019;4:1895-906.

62. Roux S, Adriaenssens EM, Dutilh BE, Koonin EV, Kropinski AM, Krupovic M, et al. Minimum Information about an Uncultivated Virus Genome (MIUViG). Nat Biotechnol. 2019;37:29-37.

63. Edwards RA, McNair K, Faust K, Raes J, Dutilh BE. Computational approaches to predict bacteriophage-host relationships. FEMS Microbiol Rev. 2016;40:258-72.

64. Pourcel C, Touchon M, Villeriot N, Vernadet JP, Couvin D, Toffano-Nioche C, et al. CRISPRCasdb a successor of CRISPRdb containing CRISPR arrays and cas genes from complete genome sequences, and tools to download and query lists of repeats and spacers. Nucleic Acids Res. 2020;48:D535-44.

65. Ågren J, Sundström A, Håfström T, Segerman B. Gegenees: fragmented alignment of multiple genomes for determining phylogenomic distances and genetic signatures unique for specified target groups. PLoS ONE. 2012;7:e39107.

66. Simmonds P, Adams MJ, Benko M, Breitbart M, Brister JR, Carstens EB, et al. Consensus statement: Virus taxonomy in the age of metagenomics. Nat Rev Microbiol. 2017;15:161-8.

67. Häring M, Rachel R, Peng X, Garrett RA, Prangishvili D. Viral diversity in hot springs of Pozzuoli, Italy, and characterization of a unique archaeal virus, Acidianus bottle-shaped virus, from a new family, the Ampullaviridae. J Virol. 2005;79:9904-11.
68. Vestergaard G, Haring M, Peng X, Rachel R, Garrett RA, Prangishvili D. A novel rudivirus, ARV1, of the hyperthermophilic archaeal genus Acidianus. Virology. 2005;336:83-92.

69. Prangishvili D, Vestergaard G, Haring M, Aramayo R, Basta T, Rachel R, et al. Structural and genomic properties of the hyperthermophilic archaeal virus ATV with an extracellular stage of the reproductive cycle. J Mol Biol. 2006;359:1203-16.

70. Vestergaard G, Aramayo R, Basta T, Haring M, Peng X, Brugger $\mathrm{K}$, et al. Structure of the acidianus filamentous virus 3 and comparative genomics of related archaeal lipothrixviruses. J Virol. 2008;82:371-81.

71. Arnold HP, Ziese U, Zillig W. SNDV, a novel virus of the extremely thermophilic and acidophilic archaeon Sulfolobus. Virology. 2000;272:409-16.

72. Mochizuki T, Sako Y, Prangishvili D. Provirus induction in hyperthermophilic archaea: characterization of Aeropyrum pernix spindle-shaped virus 1 and Aeropyrum pernix ovoid virus 1 . J Bacteriol. 2011;193:5412-9.

73. Wiedenheft B, Stedman K, Roberto F, Willits D, Gleske AK, Zoeller L, et al. Comparative genomic analysis of hyperthermophilic archaeal Fuselloviridae viruses. J Virol. 2004;78:1954-61.

74. Pauly MD, Bautista MA, Black JA, Whitaker RJ. Diversified local CRISPR-Cas immunity to viruses of Sulfolobus islandicus. Philos Trans R Soc Lond B Biol Sci. 2019;374:20180093.

75. Held NL, Whitaker RJ. Viral biogeography revealed by signatures in Sulfolobus islandicus genomes. Environ Microbiol. 2009;11: 457-66.

76. Stedman KM, Clore A, Combet-Blanc Y (2006). Biogeographical diversity of archaeal viruses. In: Logan NA, Lappin-Scott HM, Oyston PCF (eds). Prokaryotic Diversity: Mechanisms and Significance. Cambridge University Press: Cambridge. pp 131-43.

77. Snyder JC, Wiedenheft B, Lavin M, Roberto FF, Spuhler J, Ortmann AC, et al. Virus movement maintains local virus population diversity. Proc Natl Acad Sci USA. 2007;104:19102-7.

78. Medvedeva S, Liu Y, Koonin EV, Severinov K, Prangishvili D, Krupovic M. Virus-borne mini-CRISPR arrays are involved in interviral conflicts. Nat Commun. 2019;10:5204.

79. Atanasova NS, Roine E, Oren A, Bamford DH, Oksanen HM. Global network of specific virus-host interactions in hypersaline environments. Environ Microbiol. 2012;14:426-40.

80. Atanasova NS, Bamford DH, Oksanen HM. Virus-host interplay in high salt environments. Environ Microbiol Rep. 2016;8: 431-44.

81. Laidler JR, Shugart JA, Cady SL, Bahjat KS, Stedman KM. Reversible inactivation and desiccation tolerance of silicified viruses. J Virol. 2013;87:13927-9.

82. De Sordi L, Khanna V, Debarbieux L. The gut microbiota facilitates drifts in the genetic diversity and infectivity of bacterial viruses. Cell Host Microbe. 2017;22:801-8, e3.

83. Paul BG, Bagby SC, Czornyj E, Arambula D, Handa S, Sczyrba A, et al. Targeted diversity generation by intraterrestrial archaea and archaeal viruses. Nat Commun. 2015;6:6585.

84. Klein R, Rossler N, Iro M, Scholz H, Witte A. Haloarchaeal myovirus phiCh1 harbours a phase variation system for the production of protein variants with distinct cell surface adhesion specificities. Mol Microbiol. 2012;83:137-50.

85. Roux S, Brum JR, Dutilh BE, Sunagawa S, Duhaime MB, Loy A, et al. Ecogenomics and potential biogeochemical impacts of globally abundant ocean viruses. Nature. 2016;537:689-93. 